\title{
The Practicability of Transnasal Esophagoscopy and the Evaluation of Patient's Perception: A Prospective Study
}

\author{
Bahtiyar Polat ${ }^{1} \cdot$ Serdar Karahatay ${ }^{2} \cdot$ Hakan Birkent $^{2} \cdot$ Mustafa Gerek $^{2}$ \\ ${ }^{1}$ Department of Otorhinolaryngology, Head and Neck Surgery, Gelibolu Military Hospital, Gelibolu; \\ ${ }^{2}$ Department of Otorhinolaryngology, Head and Neck Surgery, Gulhane Military Medical Academy, Ankara, Turkey
}

Objectives. Transnasal esophagoscopy (TNE) is a relatively new diagnostic procedure in the evaluation of patients with globus sensation and dysphagia. Enabling doctors to examine all of the upper aerodigestive system without the need for sedation, this technique is becoming more popular among otolaryngology specialists. The aim of this study is to evaluate the practicability of TNE and tolerability of patients to the test.

Methods. The study group consisted of 314 patients who were admitted to the swallowing center of a tertiary medical institution with the symptoms of dysphagia and globus sensation. In addition to other diagnostic procedures, patients were informed of the TNE and the necessary consents were obtained. Before the examination, patients were asked to foresee the level of discomfort they would presumably feel, according to the information they had. After the TNE, patients were asked to score the real level of discomfort they experienced during the test. A visual analog scale was used to note the levels. The duration of the tests and any complications were also noted.

Results. We could not perform TNE in 12 of the 314 patients due to nasal obstruction, intractable retching and vasovagal syncope $(7,4$, and 1 patients, respectively). The average discomfort score foreseen before the test was $4.7 \pm 1.4$ (mean \pm standard deviation). The post-procedure discomfort score was 1.6 \pm 1.1 , and the difference was statistically significant $(P<0.001)$. The average time to perform the TNE was 5 minutes (range, 3 to 13 minutes). Except for minor epistaxis in 7 patients $(2 \%)$, no complications occurred.

Conclusion. According to our results, TNE is an easy and well-tolerated procedure, it may be logical to tell the patient that the procedure will be less annoying and irritating than they assume. It is also a time saving procedure with low complication rates.

Keywords. Esophagoscopy; Dysphagia; Deglutition Disorders

\section{INTRODUCTION}

Transnasal esophagoscopy (TNE) is a relatively new diagnostic procedure in the evaluation of patients with swallowing problems. Also it has gained popularity in otolaryngology because

- Received December 17, 2015

Revised January 17, 2016

Accepted January 19, 2016

- Corresponding author: Bahtiyar Polat

Department of Otolaryngology, Gelibolu Military Hospital, Gelibolu

Postcode, 17500 Çanakkale, Turkey

Tel: +90-286-566-2800, Fax: +90-286-566-2800

E-mail: bahtiyarpolat@hotmail.com the procedure is easy, safe and effective. Foremost, TNE could be performed on a patient in the sitting position, in an office setting and without the need for sedation.

Most common indications of TNE are reflux, globus sensation and dysphagia [1,2]. TNE has been performed for evaluation that the patients had swallowing problem instead of many studies [3]. In addition it is a safe and easily applicable procedure which often requires examination of diseases such as a history of head and neck cancer and caustic ingestion [1].

The aim of this study is to evaluate the practicability of TNE and tolerability of patients to the test. We evaluatedTNE-assessed discomfort, duration of the procedure and complications of TNE.

Copyright (c) 2016 by Korean Society of Otorhinolaryngology-Head and Neck Surgery.

This is an open-access article distributed under the terms of the Creative Commons Attribution Non-Commercial License (http://creativecommons.org/licenses/by-nc/4.0)

which permits unrestricted non-commercial use, distribution, and reproduction in any medium, provided the original work is properly cited. 


\section{MATERIALS AND METHODS}

The study group consisted of patients with the symptoms of dysphagia and globus sensation who were admitted to the swallowing center of a tertiary medical institution. Endoscopy was performed on these patients as a part of their clinical care. Patients with active infections were excluded. Each patient's age, gender and history of conventional endoscopy were recorded.

Examinations were performed by using the $5.9 \mathrm{~mm}$ diameter transnasal endoscopy (EG-530N; Fujinon Co., Saitama, Japan), which provided capacity for suction, irrigation, and insufflation. Examinations were performed with the participant in the sitting position in the otolaryngology office examination chair. Vital signs were obtained before the procedure. It was performed with local anesthesia in the office and without continuous monitoring. Topical anesthesia with $4 \%$ lidocaine spray was used to anesthetize the nares, and doctors waited 10 minutes to ensure complete anesthesia.

Before the examinations, the patients were asked to foresee the level of discomfort they would presumably feel, according to the information they had. After the TNE, the patients were asked to score the real level of discomfort they experienced during the test. A visual analog scale was used to note the levels (1 represented no discomfort and 10 represented severe discomfort).

We classified the ease of endoscopic nasal and esophageal insertion as easy, moderate, or difficult. In this system, easy is represented as being successful on the first attempt; moderate as being successful after several attempts; and difficult if severe pain is observed. Also regarding esophageal insertion, easy is defined as successful insertion without retching; moderate as excessive retching observed; and difficult if bleeding and/or pain observed. The duration of the procedure and any complications were also noted.

All statistical analyses were carried out using the SPSS ver. 15.0 (SPSS Inc., Chicago, IL, USA). Means and standard deviations (SDs) were reported for continuous variables with normal distributions. Medians and interquartile ranges were reported for continuous variables with skewed distributions. Statistical comparisons between the pre-procedure score and post-proce-

\section{H I G H L I G G H T S}

- Transnasal esophagoscopy (TNE) is a relatively new diagnostic tool.

- TNE is practical method in the evaluation patients who have swallowing disorder.

- TNE can be performed in the office setting without need of sedation.

- Our study results indicated that TNE is an easy, safe and well tolerated procedure. dure score were performed with a Wilcoxon test. Findings were considered significant at $P<0.05$.

\section{RESULTS}

The study group consisted of 314 patients (135 male and 179 female). Mean age was $50.8 \pm 14.9$ years. Patients presented with complaints of globus sensation and dysphagia (232 and 82 patients, respectively). We could not perform TNE in 12 of the 314 patients due to nasal obstruction, intractable retching and vasovagal syncope (7, 4, and 1 patients, respectively).

The average pre-procedure foreseen discomfort score was $4.7 \pm 1.4$ (mean \pm SD). The average post-procedure discomfort score was $1.6 \pm 1.1$ (mean $\pm \mathrm{SD}$ ), and the difference was statistically significant $(P<0.001)$.

Endoscopy procedures in 290 patients (96\%) were classified as easy. Seven procedures in nasal insertion and 2 procedures in esophageal insertion were classified as moderate. Three procedures in esophageal insertion were classified as difficult (Table 1).

The average time it took to perform the TNE was $5.15 \pm 1.6$ minutes (range, 3 to 13 minutes). In addition, pre-procedure anesthesia and preparation time was approximately 10 minutes (10.07 \pm 1.3 minutes). Epistaxis occurred in 7 patients $(2 \%)$ as a minor complication. Bleeding was controlled with direct pressure, and no major complications occurred. No post-procedure care was required.

Pathological esophageal findings included carcinoma, hiatal hernia, esophagitis, Zenker's and traction diverticulum, cervical heterotopic gastric mucosa (inlet patch), and varices, on the other hand, 270 procedures were normal (Table 2). Conventional endoscopy was performed on 38 patients by gastroenterologists. Based on previous experience from patients, TNE was also pre-

Table 1. Physician assessments

\begin{tabular}{lccc}
\hline $\begin{array}{l}\text { Physician } \\
\text { assessments }\end{array}$ & Nasal insertion & Esophageal insertion & Total \\
\hline Easy & $295(97.6)$ & $297(98.3)$ & $592(98.0)$ \\
Moderate & $7(2.4)$ & $2(0.7)$ & $9(1.5)$ \\
Difficult & 0 & $3(1.0)$ & $3(0.5)$ \\
Total & $302(100)$ & $302(100)$ & $604(100)$ \\
\hline
\end{tabular}

Values are presented as number (\%).

Table 2. Transnasal esophagoscopy findings

\begin{tabular}{lc}
\hline Finding & No. \\
\hline Esophagitis & 18 \\
Hiatal hernia & 6 \\
Esophageal carcinoma & 2 \\
Zenker's diverticulum & 2 \\
Inlet patch & 2 \\
Traction diverticulum & 1 \\
Esophageal varice & 1 \\
\hline
\end{tabular}


ferred by thirty five patients when compared with conventional endoscopy.

\section{DISCUSSION}

TNE has been used since 1990, and the first article on the topic was published by Shaker [4], a gastroenterologist, in 1994. The first otolaryngology publication emerged in 2001 [5]. The procedure, which enables doctors to examine the upper aerodigestive system without need for sedation and in an office setting, has gained popularity in otolaryngology practice in recent years. This research, which evaluated the practicability and tolerability of transnasal esophagoscopy, is the first one to be conducted in Turkey.

Otolaryngologists need to screen the esophagus for reflux, dysphagia and globus symptoms. The largest study on screening the esophagus via TNE was published by Postma et al. [2] who reported 700 consecutive patients and they suggested that TNE might replace other diagnostic tools of the esophagus in patients with reflux, globus, and dysphagia. Even if these symptoms are most indication for TNE, it can be used to many of procedure such as balloon dilation, placement of wireless $\mathrm{pH}$ capsule, biopsy suspicious lesion in the upper aerodigestive system, foreign body extraction, and tracheoesophageal puncture [6-8]. According to our study, TNE should be performed for treatment resistant reflux, globus which is long-term or with alarm symptoms such as weight loss and all patients with serious dysphagia. Especially, malignancy can be ruled out in these patients with only TNE.

TNE is performed with local anesthesia, without any sedation or patient monitoring. Nasal anesthesia should be applied before the procedure. Oropharyngeal anesthesia can be applied, but is not necessary [9]. In our study, although, we performed all procedures with only nasal anesthetic spray, it provided adequate anesthesia for upper aerodigestive tract. Therefore, we suggest that oropharyngeal anesthesia is not necessary. The most important feature of the TNE is the ability to perform it on patients while they are awake, thus avoiding adverse events of sedation such as aspiration, hypoventilation and airway obstruction.

On the other hand, TNE could not be performed on all patients. According to Belafsky et al. [10], in 4 of 100 patients $(4 \%)$ the procedure could not be performed due to nasal obstruction and vasovagal reaction; Bush and Postma [1] noted the same in 17 of 611 patients (27\%). Similarly, we could not perform TNE in 12 of the 314 patients (4\%) due to nasal obstruction, intractable retching, and vasovagal syncope $(7,4$, and 1 patients, respectively). The most common cause of failure was nasal obstruction.

The average time it took to perform the TNE was 5 minutes (range, 3 to 13 minutes) without preparation time. Generally, the total time did not exceed 20 minutes. With results similar to those of our study, Tong et al. [3] reported 6.2 minutes and Price et al. [11] reported fewer than 10 minutes. In our study, the duration of the examination was longer when the following conditions were present: 1 , need to take multiple biopsies; 2 , difficulty in esophageal passage due to Zenker's diverticulum; 3, difficulty passing through the nasal passage due to anatomical disorders; and 4, difficulty in the esophageal entrance due to a hypopharyngeal mass.

Although one case of esophageal perforation has been reported by a gastroenterologist, no major complications have been reported by otolaryngologists. Primarily, epistaxis and vasovagal reaction have been reported as minor complications $[1,11]$. Otherwise some studies reported no complications associated with the use of TNE [5,12]. Epistaxis represents the most frequent minor complication [6-8], as well as the only complication that we encountered, in 7 patients $(2 \%)$. However, laryngospasm was reported in a study that a wireless $\mathrm{pH}$ capsule being placed by TNE [6].

Aviv et al. [5] evaluated the ease of nasal and esophageal insertion using a ten point analog scale (1 represented extremely easy and 10 represented extremely difficult). The mean rating was $1.3 \pm 0.5$ for nasal insertion and $2.9 \pm 1.1$ for esophageal insertion. In another study, McPartlin et al. [12] classified the use of equipment as very easy, easy, difficult, and very difficult.They demonstrated that 7 procedures were classified as very easy; 9 procedures were classified as easy; and none of the patients were classified as difficult or very difficult. In our study, endoscopy procedures in 290 patients were classified as easy, which is approximately $96 \%$. Esophageal insertion was especially difficult in the presence of hypopharyngeal cancer. These results indicate that TNE is an easy procedure.

In this prospective study, as in other studies, the actual postprocedure discomfort score was as low as $1.6 \pm 1.1[3,5,11]$. These results indicate that TNE was well tolerated by patients. Although there are several studies aboutTNE, none of them has evaluated the patient's perception of the procedure. This is the unique part of our study. In addition, in our study, before the examination, the patients were asked to foresee the level of discomfort they would presumably feel, according to the information they had. The average discomfort score foreseen before the test was as high as $4.7 \pm 1.4$.

The fact that the pre-procedure scores were higher than the post-procedure scores in our study suggests that patients perceive transnasal esophagoscopy as more difficult than it actually is. These patients must be given exact information about procedures in order to reduce their anxiety related to endoscopy.

In conclusion, TNE is an easy, quick, and well-tolerated procedure that can be carried out with low complication rates. According to our results, it may be logical to tell patients that the procedure will be less annoying and irritating than they may assume. 


\section{CONFLICT OF INTEREST}

No potential conflict of interest relevant to this article was reported.

\section{REFERENCES}

1. Bush CM, Postma GN. Transnasal esophagoscopy. Otolaryngol Clin North Am. 2013 Feb;46(1):41-52.

2. Postma GN, Cohen JT, Belafsky PC, Halum SL, Gupta SK, Bach KK, et al.Transnasal esophagoscopy: revisited (over 700 consecutive cases). Laryngoscope. 2005 Feb;115(2):321-3.

3. Tong MC, Gao H, Lin JS, Ng LK, Chan HS, Ng SK. One-stop evaluation of globus pharyngeus symptoms with transnasal esophagoscopy and swallowing function test. J Otolaryngol Head Neck Surg. 2012 Feb;41(1):46-50.

4. Shaker R. Unsedated trans-nasal pharyngoesophagogastroduodenoscopy (T-EGD): technique. Gastrointest Endosc. 1994 MayJun;40(3):346-8.

5. Aviv JE, Takoudes TG, Ma G, Close LG. Office-based esophagoscopy: a preliminary report. Otolaryngol Head Neck Surg. 2001 Sep;
125(3):170-5.

6. Belafsky PC, Allen K, Castro-Del Rosario L, Roseman D. Wireless $\mathrm{pH}$ testing as an adjunct to unsedated transnasal esophagoscopy: the safety and efficacy of transnasal telemetry capsule placement. Otolaryngol Head Neck Surg. 2004 Jul;131(1):26-8.

7. Rees CJ. In-office unsedated transnasal balloon dilation of the esophagus and trachea. Curr Opin Otolaryngol Head Neck Surg. 2007 Dec;15(6):401-4.

8. Bach KK, Postma GN, Koufman JA. In-office tracheoesophageal puncture using transnasal esophagoscopy. Laryngoscope. 2003 Jan; 113(1):173-6

9. Rosen CA,Amin MR, Sulica L, Simpson CB, MeratiAL, Courey MS, et al.Advances in office-based diagnosis and treatment in laryngology. Laryngoscope. 2009 Nov;119 Suppl 2:S185-212.

10. Belafsky PC, Postma GN, Daniel E, Koufman JA.Transnasal esophagoscopy. Otolaryngol Head Neck Surg. 2001 Dec;125(6):588-9.

11. Price T, Sharma A, Snelling J, Bennett AM, Qayyum A, Bradnam T, et al. How we do it: the role of trans-nasal flexible laryngo-oesophagoscopy (TNFLO) in ENT: one year's experience in a head and neck orientated practice in the UK. Clin Otolaryngol. 2005 Dec;30(6): 551-6.

12. McPartlin DW, Nouraei SA, Tatla T, Howard DJ, Sandhu GS. How we do it: transnasal fibreoptic oesophagoscopy. Clin Otolaryngol. 2005 Dec;30(6):547-50. 